\title{
Anethole restores delayed gastric emptying and impaired gastric accommodation
}

\section{in rodents}

Teita Asano ${ }^{\mathrm{a}, 1, *}$, Shuji Aida ${ }^{\mathrm{a}, 1}$, Shintaro Suemasu ${ }^{\mathrm{a}}$, and Tohru Mizushima ${ }^{\mathrm{b}}$

${ }^{a}$ Division of Drug Discovery and Development, Faculty of Pharmacy, Keio University, 1-5-30 Shibakoen, Minato-ku, Tokyo 105-8512, Japan

${ }^{\mathrm{b}}$ LTT Bio-Pharma Co., Ltd., Shiodome Building 3F, 1-2-20 Kaigan, Minato-ku, Tokyo 105-0022, Japan

${ }^{1}$ These authors contributed equally to the work.

* Corresponding author. Division of Drug Discovery and Development, Faculty of Pharmacy, Keio University, 1-5-30 Shibakoen, Minato-ku, Tokyo 105-8512, Japan. Tel \& Fax: +81 35400 2620; E-mail: asano-ti@pha.keio.ac.jp (T. Asano). 


\begin{abstract}
Functional dyspepsia (FD), a functional gastrointestinal disorder, is characterized by persistent or recurrent postprandial upper abdominal discomfort and epigastric pain. The high prevalence of FD and associated healthcare costs suggests that treatment of this condition by methods other than prescribed medicines, such as natural products, could be beneficial. Delayed gastric emptying and impaired gastric accommodation play important roles in the development of FD. Anethole (1-methoxy-4-((E)-propenyl)benzene), a major component of essential fennel oil, has been used as a flavoring, in alcoholic beverage production and in pharmaceutical formulations for many years. In this study, we examined the effects of anethole on delayed gastric emptying and impaired gastric accommodation in rodents. Oral administration of anethole improved clonidine-induced delayed gastric emptying but did not affect normal gastric emptying in mice. Fennel oil and Anchu-san (a Japanese herbal medicine containing anethole) also restored delayed gastric emptying. Furthermore, oral administration of anethole stimulated gastric accommodation in rats. These results suggest that anethole could be beneficial for the treatment of FD.
\end{abstract}

\title{
Keywords
}

Anethole; gastric emptying; gastric accommodation; functional dyspepsia

\footnotetext{
Abbreviations

EPS, epigastric pain syndrome; 5-HT, serotonin; FD, functional dyspepsia; m-CPBG, mchlorophenylbiguanide; PDS, postprandial-distress syndrome.
} 


\section{Introduction}

Functional dyspepsia (FD) is a disease with persistent or recurrent postprandial upper abdominal discomfort and epigastric pain in the absence of any organic, systemic, or metabolic diseases. The prevalence of dyspepsia in the general population is remarkably high (15-20\%), and the majority of these patients are diagnosed with FD [1]. Treatments for FD, including pharmacotherapy, have not been fully efficacious to date [1], and FD significantly reduces patients' quality of life and imposes a considerable economic burden on the healthcare system [2]. Thus, the identification of effective therapies (such as natural products) that do not involve prescription drugs may be beneficial.

FD is categorized into postprandial-distress syndrome (PDS) and epigastric pain syndrome (EPS), based on the predominant symptoms (postprandial fullness/early satiation in PDS, and epigastric pain/burning in EPS) [3, 4]. Delayed gastric emptying and impaired gastric accommodation to a meal or visceral hypersensitivity to gastric distension have been suggested to be involved in the pathogenesis of PDS or EPS, respectively [5].

Serotonin (5-HT) and dopamine receptors affect gastric emptying and are suggested to mediate delayed gastric emptying in $\mathrm{FD}$ patients $[6,7]$. Consequently, drugs targeting these molecules and their receptors have been developed as anti-FD drugs. For example, mosapride citrate (mosapride), cisapride monohydrate (cisapride) and tegaserod are 5- $\mathrm{HT}_{4}$ receptor agonists, while domperidone and itopride hydrochloride (itopride) are dopamine $\mathrm{D}_{2}$ receptor antagonists; these drugs are in current use (or have been used previously) to treat FD patients in certain countries [8]. However, for the treatment of FD patients using these drugs has resulted in 
unsatisfactory outcomes [9]. Given that their corresponding endogenous molecules regulate other physiological functions, however, the use of these drugs is restricted clinically due to potential adverse effects $[10,11]$. Thus, safer protocols for the treatment of FD, such as those incorporating natural products, should be developed.

Acotiamide hydrochloride (acotiamide), the first drug approved to treat FD in Japan, is an acetylcholinesterase inhibitor [12]; the importance of impaired gastric accommodation in the pathogenesis of FD is supported by recent findings that acotiamide stimulates gastric accommodation [13]. Thus, drugs that can improve delayed gastric emptying as well as impaired gastric accommodation are potential candidates for the treatment of FD.

We recently screened for clinically used drugs with the ability to improve delayed gastric emptying in rats and identified aldioxa [14]. This screening procedure also identified anethole (1-methoxy-4-((E)-propenyl)-benzene), a major component of essential oils of anise and fennel and has been used in flavoring, alcoholic beverage production and pharmaceutical formulations for many years [15]. In this study, we examined the effects of anethole on delayed gastric emptying and impaired gastric accommodation in rodents. Oral administration of anethole, fennel oil and Anchu-san (a Japanese herbal medicine containing anethole) improved clonidine-induced delayed gastric emptying. Anethole also stimulated gastric accommodation in rats. Based on these results, we propose that anethole, fennel oil and Anchu-san may be beneficial for the treatment of FD. 


\section{Materials and Methods}

Chemicals and animals. Methylcellulose, carboxymethylcellulose sodium, ethyl carbamate (urethane), clonidine, fennel oil and phenol red were obtained from Wako Pure Chemical Industries (Osaka, Japan). Cisapride, m-chlorophenylbiguanide (mCPBG), neostigmine bromide (neostigmine), GR113808 and mosapride were purchased from Sigma (St. Louis, MO). Itopride, dopamine hydrochloride (dopamine) and ramosetron were obtained from LKT laboratories Inc. (St Paul, MN). Saline was from Otsuka Pharmaceutical Co. Ltd. (Tokyo, Japan) and anethole was from Tokyo Chemical Industry Co. Ltd. (Tokyo, Japan). Amplite ${ }^{\mathrm{TM}}$ Colorimetric Assay kit for acetylcholinesterase was from AAT Bioquest ${ }^{\circledR}$ Inc. (Sunnyvale, CA). Tsumura Anchusan extract (Anchu-san, TJ-5) was purchased from Tsumura \& Co. (Tokyo, Japan). Acotiamide was gifted from Zeria Pharmaceutical Co. Ltd. (Saitama, Japan). ICR mice (7-week-old males, 30-35 g) and Sprague-Dawley rats (10-week-old males, 270-320 g) were obtained from Sankyo Labo Service Co. Inc. (Tokyo, Japan). Animals were housed under conditions of controlled temperature $\left(22-24^{\circ} \mathrm{C}\right)$ and illumination $(12 \mathrm{~h}$ light cycle) for 1 or 2 weeks prior to experiments. The experiments and procedures described here were performed in accordance with the National Institutes of Health Guide for the Care and Use of Laboratory Animals and were approved by the Animal Care Committee of Keio University.

Measurement of gastric emptying with the phenol red method. Gastric emptying was also monitored by use of the phenol red method as previously described [14]. Mice were fasted for $18 \mathrm{~h}$ and had free access to water, following which $1.5 \%$ carboxymethylcellulose sodium salt containing $0.05 \%$ phenol red $(0.5 \mathrm{ml} / \mathrm{mouse})$ was 
intragastrically administered. Twenty minutes later, mice were sacrificed and stomach was harvested. Gastric content collected and centrifuged at 3,000 rpm for 15 min after treatment with $10 \mathrm{ml}$ of $0.1 \mathrm{M} \mathrm{NaHCO}_{3}$. The amount of phenol red in the supernatant was determined based on the absorbance at $558 \mathrm{~nm}$ measured using a microplate reader (Multiscan GO, Thermo Scientific, Yokohama, Japan) as described previously [14].

Animal models for delayed gastric emptying. Three different animal models of delayed gastric emptying were used, with delayed emptying induced by clonidine, dopamine or m-CPBG. In the clonidine-induced delayed gastric emptying model, 30 $\mu \mathrm{g} / \mathrm{kg}$ clonidine was subcutaneously administered to mice 5 min prior to the administration of phenol red. In the dopamine or m-CPBG-induced delayed gastric emptying model, $10 \mathrm{mg} / \mathrm{kg}$ of dopamine or $\mathrm{m}-\mathrm{CPBG}$ were intraperitoneally administered to mice, 5 or 10 min prior to the administration of phenol red, respectively. In any of these animal models, anethole (in $0.06 \%$ Tween-80) or other drugs (in $1 \%$ methylcellulose) was administered intragastrically at $10 \mathrm{~mL} / \mathrm{kg} 1 \mathrm{~h}$ before the administration of phenol red.

Inhibitory effect on acetylcholinesterase. A stomach-derived fraction with acetylcholinesterase was prepared from six mice as described previously [16], with some modifications. Briefly, the forestomach was removed from fasted mice and homogenized in a 10-fold volume of $0.1 \mathrm{mM}$ sodium phosphate buffer ( $\mathrm{pH}$ 6.9) with 10 mM EDTA. The homogenate was centrifuged for $60 \mathrm{~min}$ and precipitate was washed twice with buffer. After treatment at $4^{\circ} \mathrm{C}$ for 60 min with buffer containing $1 \%$ Triton $\mathrm{X}$ 100, supernatant was obtained by centrifugation and was used as a stomach-derived 
fraction with acetylcholinesterase. Protein concentration was determined by the Bradford method [17].

Acetylcholinesterase activity was measured using an assay kit as described previously with some modifications [16]. A $50 \mu \mathrm{L}$ aliquot of assay buffer (sodium phosphate buffer (pH 7.6) containing $10 \mathrm{mM}$ EDTA, $2 \mathrm{mM}$ tetraisopropyl pyrophosphoramide (butyrylcholinesterase inhibitor) and $1 \mathrm{mM} \mathrm{N}$-ethylmaleimide) was mixed with $50 \mu \mathrm{L}$ test compound solution (dissolved in 1\% DMSO) and $50 \mu \mathrm{L}$ of stomach-derived fraction with acetylcholinesterase $(25 \mathrm{mU} / \mathrm{mL})$ and incubated at $30^{\circ} \mathrm{C}$ for $1 \mathrm{~min}$. The reaction was then started by adding $50 \mu \mathrm{L}$ of acetylthiocholine mixture

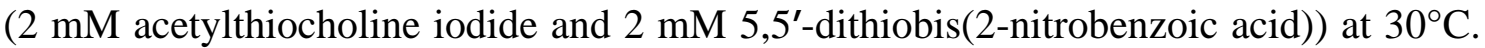
The increase in absorbance at $412 \mathrm{~nm}$ was measured using a spectrophotometer. The increase in absorbance per min was determined from the profile obtained from 35 to 95 $\mathrm{s}$ after addition of acetylthiocholine mixture. Inhibition rate $(\%)$ was calculated as the ratio of acetylthiocholine activity in the presence of a test compound relative to control activity in absence of the test compound (1\% DMSO).

Gastric accommodation test. Gastric accommodation was determined as described previously with some modifications [18]. Briefly, rats fasted for $18 \mathrm{~h}$ were orally administered each test compound in combination with $0.06 \%$ Tween-80 (for anethole) or $1 \%$ methylcellulose (for other drugs) at $2.5 \mathrm{~mL} / \mathrm{kg}$. Following a $1 \mathrm{~h}$ interval (control) or $1 \mathrm{~h}$ of being subjected to wrap restraint stress, rats were anesthetized with urethane $(1.5 \mathrm{~g} / \mathrm{kg})$. A polyethylene bag (maximum volume, $5 \mathrm{~mL}$; maximum diameter, $3 \mathrm{~cm}$ ) connected to a pair of polyvinyl tubes was introduced into the stomach, with the tubes exiting via the mouth. Air was injected into the balloon to allow placement of the 
balloon in the stomach. After a 10 min recovery period, the balloon tubes were connected to a barostat (Barostat Distender IIR, Starmedical, Tokyo, Japan) and the pressure inside the balloon was increased stepwise at 1 min intervals. The balloon volume increased gradually until it reached a plateau. The difference in balloon volume $(\mathrm{mL})$ between the initial and the final (plateau) levels was defined as gastric accommodation.

Statistical analysis. Each value is expressed as the mean \pm S.E.M. Two-way analysis of variance followed by the Tukey test or the Student $t$-test for unpaired results was used to evaluate differences between more than two groups or between two groups, respectively. Differences were considered to be significant for values of $\mathrm{P}<0.05$. 


\section{Results}

\section{Effect of anethole on clonidine-induced delayed gastric emptying.}

The effect of oral administration of anethole on clonidine-induced delayed gastric emptying was examined by the phenol red method. As shown in Fig. 1A, administration of clonidine delayed gastric emptying, and oral pre-administration of anethole restored gastric emptying in a dose-dependent manner. We confirmed that acotiamide also restored gastric emptying (Fig. 1A). We also examined the effect of anethole on the basal level of gastric emptying (without clonidine treatment). Administration of cisapride, but not anethole, accelerated normal gastric emptying in normal mice (Fig. 1B).

As anethole is a major component of essential oil of fennel, we examined the effect of fennel oil on clonidine-induced delayed gastric emptying. As shown in Fig. 2B, oral pre-administration of fennel oil restored gastric emptying in the presence of clonidine in a dose-dependent manner. Since the content of anethole in fennel oil used in this study is about $86 \%$, this stimulatory effect of fennel oil could be explained by the anethole component. Anchu-san, a Japanese herbal medicine containing fennel oil, also restored gastric emptying in the presence of clonidine in a dose-dependent manner (Fig. 2B).

\section{Mechanism for the stimulatory effect of anethole on delayed gastric emptying. As} described in the introduction, a number of molecular targets of drugs that could restore gastric emptying have been proposed, particularly those involving $\mathrm{D}_{2}, 5-\mathrm{HT}_{3}$ and $5-\mathrm{HT}_{4}$ receptors and acetylcholinesterase. We examined the involvement of these molecules in 
the stimulatory effect of anethole on gastric emptying. To test the involvement of the 5$\mathrm{HT}_{4}$ receptor, we examined the effect of a selective 5-HT4 receptor antagonist (GR113808) [19] on the stimulatory effect of anethole on gastric emptying. As shown in Fig. 3A, anethole suppressed clonidine-induced delayed gastric emptying, even in the presence of GR113808. However, cisapride (a 5-HT4 receptor agonist) did not affect clonidine-induced delayed gastric emptying in the presence of GR113808 (Fig. 3A).

To test the involvement of the $5-\mathrm{HT}_{3}$ or $\mathrm{D}_{2}$ receptors, we examined the effect of anethole on $\mathrm{m}-\mathrm{CPBG}$ (5-HT3 receptor agonist)- or dopamine-induced delayed gastric emptying. As shown in Fig. 3B and $\mathrm{C}$, anethole had no effect on delayed gastric emptying induced by these treatments. However, administration of ramosetron $\left(5-\mathrm{HT}_{3}\right.$ receptor antagonist) or itopride ( $\mathrm{D}_{2}$ receptor antagonist) suppressed the delayed gastric emptying induced by m-CPBG or dopamine, respectively (Fig. 3B and C). The results suggest that anethole restores gastric emptying independently of $\mathrm{D}_{2}, 5-\mathrm{HT}_{3}$ and $5-\mathrm{HT}_{4}$ receptors.

To test the involvement of acetylcholinesterase, we examined the effect of anethole on acetylcholinesterase activity. As shown in Fig. 3D, anethole did not affect acetylcholinesterase activity, even at the highest concentration used $(0.8 \mathrm{mM})$. However, acotiamide or neostigmine (an acetylcholinesterase inhibitor) inhibited acetylcholinesterase activity; the concentration of each of drug required to inhibit the activity was similar to that reported previously [16]. The results suggest that anethole restores gastric emptying independently of acetylcholinesterase.

Effect of anethole on gastric accommodation in rats. We examined the effect of anethole on gastric accommodation (as adaptive relaxation) using a barostat apparatus. 
As shown in Fig. 4A, increased balloon pressure resulted in an increase in balloon volume. The pre-administration of acotiamide potentiated this increase, as described previously [14], indicating that acotiamide stimulates gastric accommodation. Similarly, pre-administration of anethole potentiated gastric accommodation (Fig. 4A).

We subsequently examined the effect of anethole on gastric accommodation in rats subjected to wrap restraint stress. As shown in Fig. 4B, gastric accommodation was inhibited in rats subjected to wrap restraint stress compared with control rats. Furthermore, pre-administration of anethole or acotiamide stimulated gastric accommodation in these animals (Fig. 4B). These results suggest that anethole stimulates gastric accommodation under both normal and stress conditions. 


\section{Discussion}

In this study, we found that the oral administration of anethole suppressed clonidine-induced delayed gastric emptying in mice, suggesting that anethole may be therapeutically beneficial for FD patients. We also found that fennel oil and Anchu-san restored delayed gastric emptying. To identify the molecular target of anethole that mediates its effect on delayed gastric emptying, we performed several experiments. Since 5- $\mathrm{HT}_{4}$ receptor agonists, 5- $\mathrm{HT}_{3}$ receptor antagonists and $\mathrm{D}_{2}$ receptor antagonists are known to restore delayed gastric emptying, we tested the possibility that anethole acts as a 5-HT4 receptor agonist, $5-\mathrm{HT}_{3}$ receptor antagonist or $\mathrm{D}_{2}$ receptor antagonist. However, these possibilities were ruled out by observations that anethole restored gastric emptying even in the presence of a $5-\mathrm{HT}_{4}$ receptor antagonist, but did not affect delayed gastric emptying induced by a 5- $\mathrm{HT}_{3}$ receptor or $\mathrm{D}_{2}$ receptor agonist. From the results shown in Fig. 3D, we further suggest that anethole restores gastric emptying independently of acetylcholinesterase.

In addition to delayed gastric emptying, impaired gastric accommodation plays an important role in the pathogenesis of FD, particularly PDS [20]. We therefore examined the effect of anethole on gastric accommodation and found that, as well as acotiamide, orally administered anethole stimulated gastric accommodation in both control rats and rats in which gastric accommodation was impaired by subjection to wrap restraint stress. Since anethole did not inhibit acetylcholinesterase activity, as shown in Fig. 3D, it may stimulate gastric accommodation independently of acetylcholinesterase. 
In conclusion, the results of this study suggest that anethole may be a potential candidate drug for treating FD, based on its stimulatory influence on both gastric emptying and gastric accommodation.

\section{Acknowledgments}

We thank Dr. Masayuki Uchida (Food Science Institute, Meiji Co. Ltd.) for technical advice on gastric accommodation analysis. This work was supported by Grants-in-Aid for Scientific Research from the Ministry of Health, Labour and Welfare of Japan, as well as the Center of Innovation Program from Japan Science and Technology Agency, Scientific Technique Research Promotion Program for Agriculture, Forestry and Food Industry, and Grants-in-Aid for Scientific Research from the Ministry of Education, Culture, Sports, Science and Technology of Japan.

\section{Author contributions}

Conception and design: TA, SA, SS and TM; analysis and interpretation: TA, SA and TM; drafting the manuscript for important intellectual content: TA and TM.

\section{Additional information}

Competing financial interests: The authors declare no competing financial interests. 


\section{References}

[1] H.B. El-Serag, N.J. Talley, Systemic review: the prevalence and clinical course of functional dyspepsia, Aliment. Pharmacol. Ther. 19 (2004) 643-654.

[2] B.E. Lacy, K.T. Weiser, A.T. Kennedy, M.D. Crowell, N.J. Talley, Functional dyspepsia: the economic impact to patients, Aliment. Pharmacol. Ther. 38 (2013) 170 177.

[3] R. Bisschops, G. Karamanolis, J. Arts, P. Caenepeel, K. Verbeke, J. Janssens, J. Tack, Relationship between symptoms and ingestion of a meal in functional dyspepsia, Gut, 57 (2008) 1495-1503.

[4] R.S. Choung, G.R. Locke, C.D. Schleck, A.R. Zinsmeister, N.J. Talley, Do distinct dyspepsia subgroups exist in the community? A population-based study, Am. J.

Gastroenterol. 102 (2007) 1983-1989.

[5] S. Timmons, R. Liston, K.J. Moriarty, Functional dyspepsia: motor abnormalities, sensory dysfunction, and therapeutic options, Am. J. Gastroenterol. 99 (2004) 739-749.

[6] M. Tonini, L. Cipollina, E. Poluzzi, F. Crema, G.R. Corazza, F. De Ponti, Review article: clinical implications of enteric and central D2 receptor blockade by antidopaminergic gastrointestinal prokinetics, Aliment Pharmacol Ther, 19 (2004) 379390.

[7] S. O'Mahony, T.G. Dinan, P.W. Keeling, A.S. Chua, Central serotonergic and noradrenergic receptors in functional dyspepsia, World J Gastroenterol, 12 (2006) 26812687.

[8] R. Brun, B. Kuo, Functional dyspepsia, Therap Adv Gastroenterol, 3 (2010) 145164.

[9] G. Holtmann, J. Gapasin, Failed therapy and directions for the future in dyspepsia, Dig Dis, 26 (2008) 218-224.

[10] S. Bran, W.A. Murray, I.B. Hirsch, J.P. Palmer, Long QT syndrome during highdose cisapride, Arch Intern Med, 155 (1995) 765-768.

[11] H. Vanheel, J. Tack, Therapeutic options for functional dyspepsia, Dig Dis, 32 (2014) 230-234.

[12] E. Altan, T. Masaoka, R. Farre, J. Tack, Acotiamide, a novel gastroprokinetic for the treatment of patients with functional dyspepsia: postprandial distress syndrome, Expert Rev Gastroenterol Hepatol, 6 (2012) 533-544.

[13] H. Kusunoki, K. Haruma, N. Manabe, H. Imamura, T. Kamada, A. Shiotani, J. Hata, H. Sugioka, Y. Saito, H. Kato, J. Tack, Therapeutic efficacy of acotiamide in patients with functional dyspepsia based on enhanced postprandial gastric accommodation and emptying: randomized controlled study evaluation by real-time ultrasonography, Neurogastroenterol Motil, 24 (2012) 540-545, e250-541.

[14] T. Asano, S. Aida, S. Suemasu, K. Tahara, K. Tanaka, T. Mizushima, Aldioxa improves delayed gastric emptying and impaired gastric compliance, pathophysiologic mechanisms of functional dyspepsia, Sci Rep, 5 (2015) 17519.

[15] M. De Vincenzi, M. Silano, F. Maialetti, B. Scazzocchio, Constituents of aromatic plants: II. Estragole, Fitoterapia, 71 (2000) 725-729.

[16] M. Kawachi, Y. Matsunaga, T. Tanaka, Y. Hori, K. Ito, K. Nagahama, T. Ozaki, N. Inoue, R. Toda, K. Yoshii, M. Hirayama, Y. Kawabata, M. Takei, Acotiamide 
hydrochloride (Z-338) enhances gastric motility and emptying by inhibiting acetylcholinesterase activity in rats, Eur J Pharmacol, 666 (2011) 218-225.

[17] M.M. Bradford, A rapid and sensitive method for the quantitation of microgram quantities of protein utilizing the principle of protein-dye binding, Anal Biochem, 72 (1976) 248-254.

[18] M. Uchida, K. Shimizu, Evaluation of adaptive relaxation of the rat stomach using an orally inserted balloon instead of surgical intervention by demonstrating the effects of capsaicin and Nomega-nitro-L-arginine methylester, J Smooth Muscle Res, 48 (2012) 97-104.

[19] J.D. Gale, C.J. Grossman, J.W. Whitehead, A.W. Oxford, K.T. Bunce, P.P. Humphrey, GR113808: a novel, selective antagonist with high affinity at the 5-HT4 receptor, Br J Pharmacol, 111 (1994) 332-338.

[20] S. Kindt, J. Tack, Impaired gastric accommodation and its role in dyspepsia, Gut, 55 (2006) 1685-1691. 


\section{Figure Legends}

Figure 1. Effect of anethole on clonidine-induced delayed or normal gastric emptying. Mice fasted for $18 \mathrm{~h}$ were orally administered the indicated dose (A) or 0.3 $\mathrm{mg} / \mathrm{kg}$ (B) of anethole, $300 \mathrm{mg} / \mathrm{kg}$ of acotiamide (A), $5 \mathrm{mg} / \mathrm{kg}$ of cisapride (B) or vehicle $(0.06 \%$ Tween-80) (A, B). Fifty-five minutes after each drug administration, delayed gastric emptying was induced by the subcutaneous administration of clonidine (30 $\mu \mathrm{g} / \mathrm{kg}$ ). Control mice were subcutaneously administered saline (A). Sixty minutes after each tested drug administration, gastric emptying was determined using the phenol red method (A, B). Values are mean \pm S.E.M. $* P<0.05 ; * * P<0.01$.

Figure 2. Effect of fennel oil or Anchu-san on clonidine-induced delayed gastric emptying. Mice fasted for $18 \mathrm{~h}$ were orally administered the indicated dose of fennel oil $(\mathrm{mg} / \mathrm{kg})(\mathrm{A})$, Anchu-san $(\mathrm{mg} / \mathrm{kg})(\mathrm{B})$ or vehicle $(0.06 \%$ Tween-80) (A, B). Fifty-five minutes after each drug administration, delayed gastric emptying was induced by the subcutaneous administration of clonidine $(30 \mu \mathrm{g} / \mathrm{kg})$. Control mice were subcutaneously administered saline. Sixty minutes after administration of fennel oil or Anchu-san, gastric emptying was determined using the phenol red method (A, B). Values are mean \pm S.E.M. $* P<0.05 ; * * P<0.01$. n.s., not significant.

Figure 3. Independence of 5-HT, $5-\mathrm{HT}_{3}$ and $\mathrm{D}_{2}$ receptors or acetycholinesterase activity on stimulatory effect of anethole on gastric emptying. Mice fasted for $18 \mathrm{~h}$ were orally administered anethole $(0.3 \mathrm{mg} / \mathrm{kg})(\mathrm{A}-\mathrm{C})$, cisapride $(5 \mathrm{mg} / \mathrm{kg})(\mathrm{A})$, ramosetron $(0.1 \mathrm{mg} / \mathrm{kg})(\mathrm{B})$, itopride $(200 \mathrm{mg} / \mathrm{kg})(\mathrm{C})$ or vehicle $(0.06 \%$ Tween-80) (A- 
C). GR113808 (10 mg/kg, a selective 5-HT4 antagonist) was administered $10 \mathrm{~min}$ before each drug administration (A). Fifty-five (A, C) or forty-five (B) minutes after each drug administration, delayed gastric emptying was induced by administration of clonidine $(30 \mu \mathrm{g} / \mathrm{kg})(\mathrm{A}), \mathrm{m}-\mathrm{CPBG}\left(10 \mathrm{mg} / \mathrm{kg}\right.$, a selective $5-\mathrm{HT}_{3}$ agonist) (B) or dopamine (10 $\mathrm{mg} / \mathrm{kg})$ (C) and examined using the phenol red method. (D), acetylcholinesterase-containing fraction was prepared from mouse stomach and incubated with the indicated concentration of anethole, neostigmine or acotiamide for $30 \mathrm{~min}$ at $30^{\circ} \mathrm{C}$. The inhibitory effect of compounds on acetylcholinesterase activity was determined $(n=3)$. Values are mean \pm S.E.M. $* P<0.05$; $* * P<0.01$. n.s., not significant.

Figure 4. Effect of anethole on gastric accommodation in rats. Rats fasted for $18 \mathrm{~h}$ were orally administered the indicated dose of anethole $(\mathrm{mg} / \mathrm{kg})(\mathrm{A}, \mathrm{B})$, acotiamide $(300$ $\mathrm{mg} / \mathrm{kg})(\mathrm{A})$ or vehicle $(0.06 \%$ Tween-80) (A, B). Rats were subjected to wrap restraint stress (WRS) for $1 \mathrm{~h}$ (B). Gastric accommodation was measured $1 \mathrm{~h}$ after the administration of each drug. Values are mean \pm S.E.M. $\$, *, \uparrow, \# P<0.05 ; * *, \# \# P<$ 0.01. \$, anethole (0.03) versus vehicle; *, anethole (0.3) versus vehicle; $\uparrow$, anethole (3) versus vehicle; \#, acotiamide (300) versus vehicle. 
Figure 1

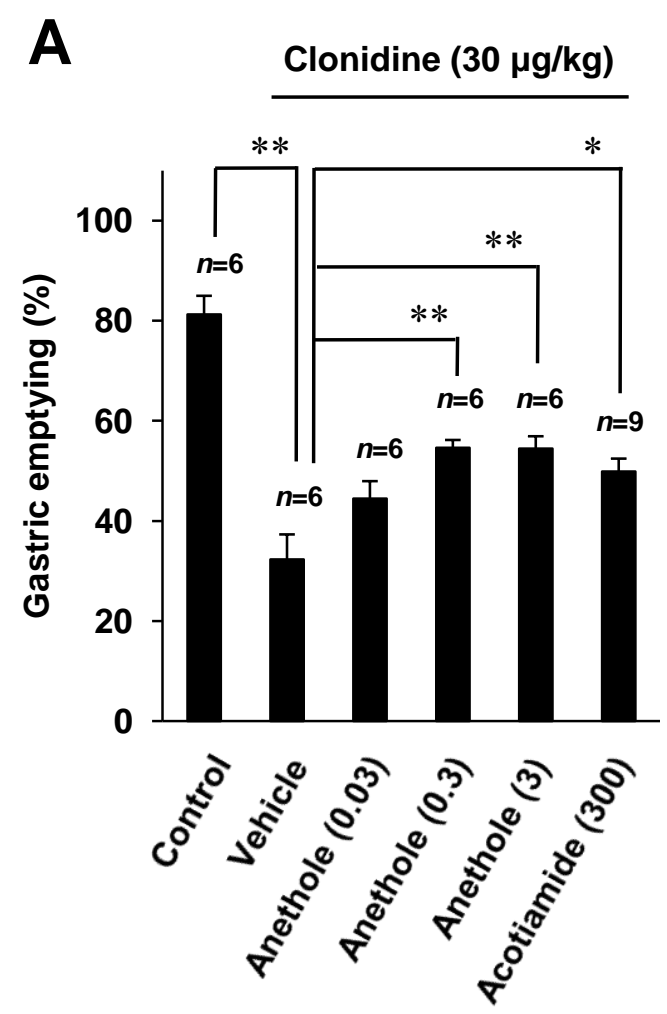

B

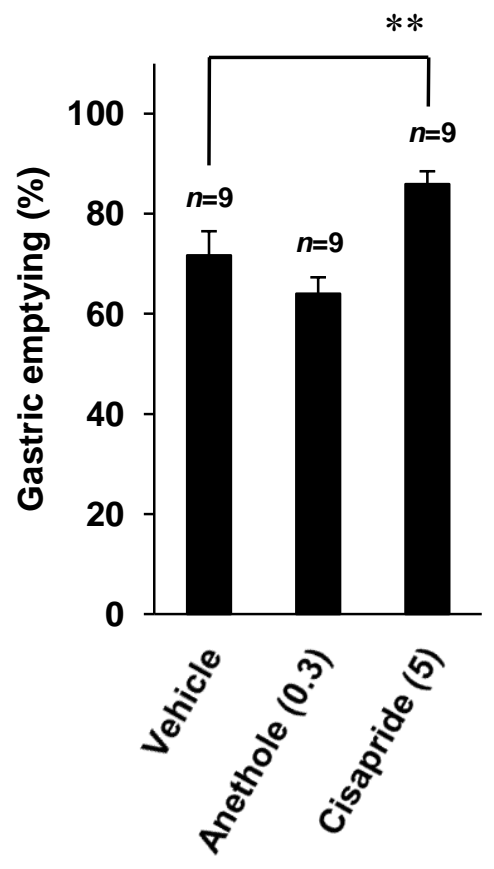


Figure 2
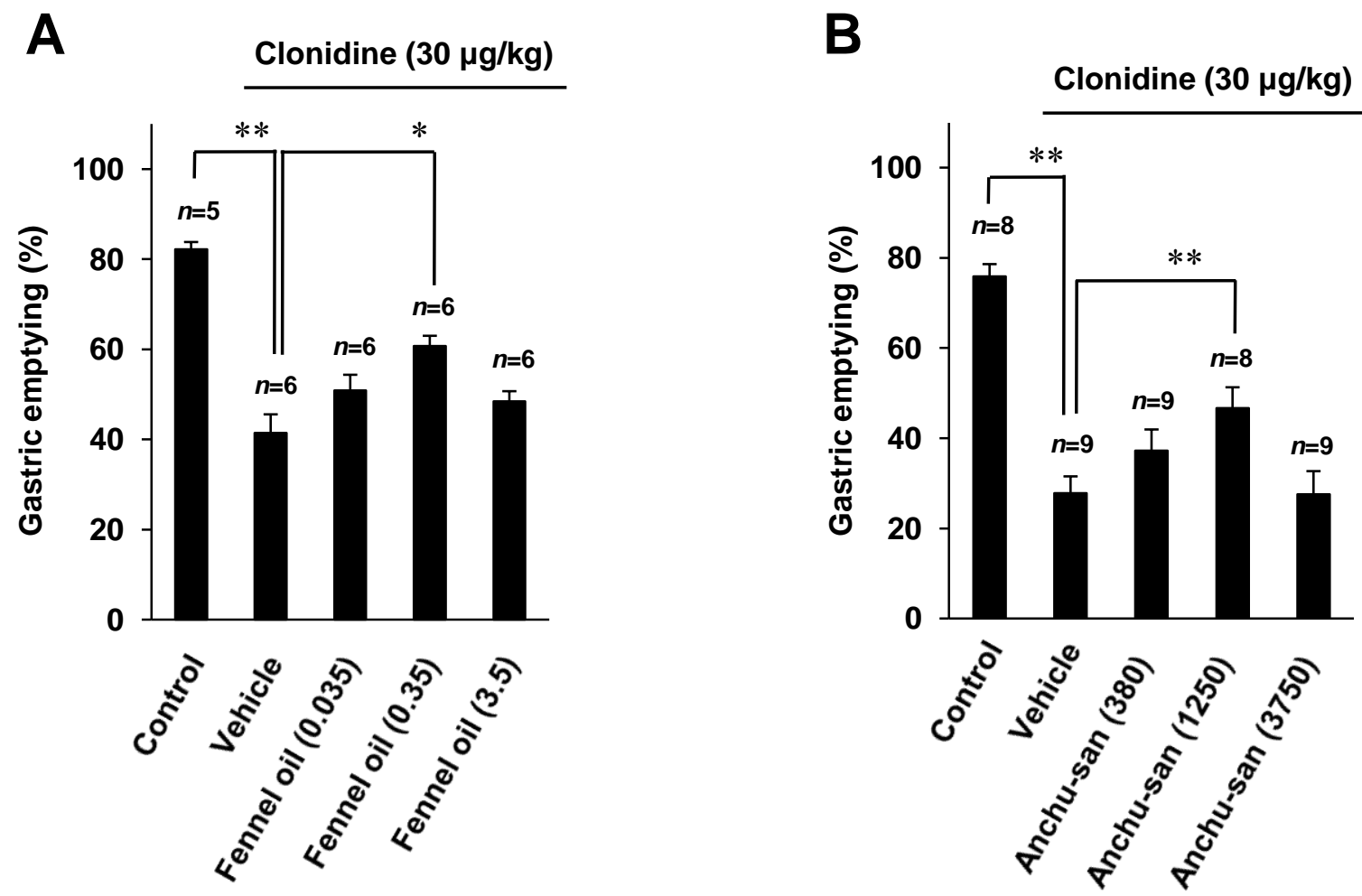
A

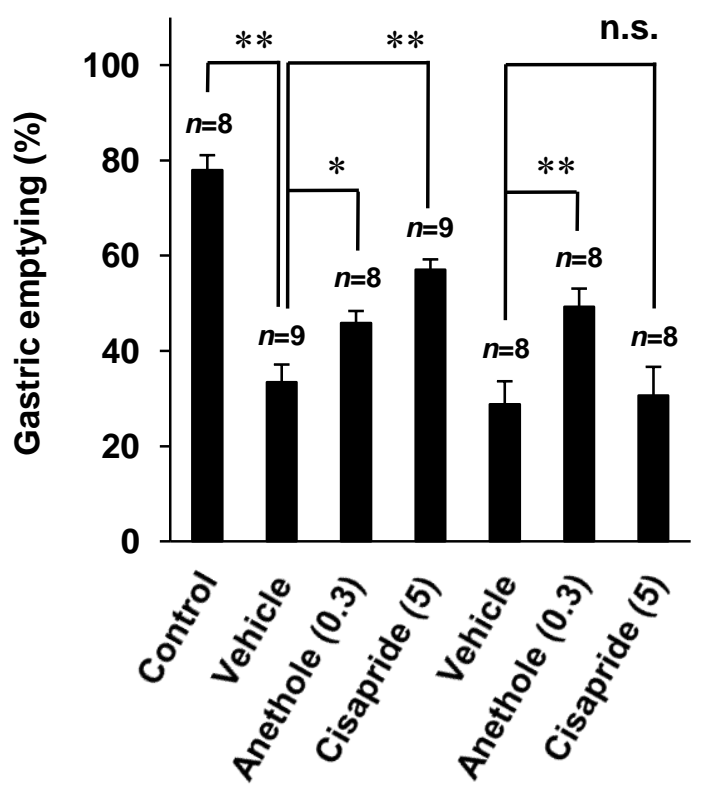

GR113808

(+)
C

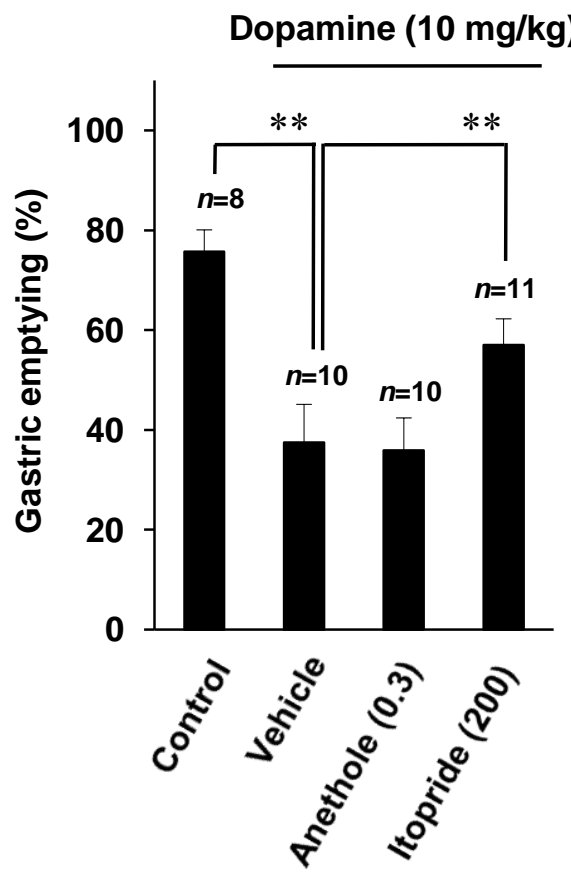

B $\mathrm{m}-\mathrm{CPBG}(10 \mathrm{mg} / \mathrm{kg})$

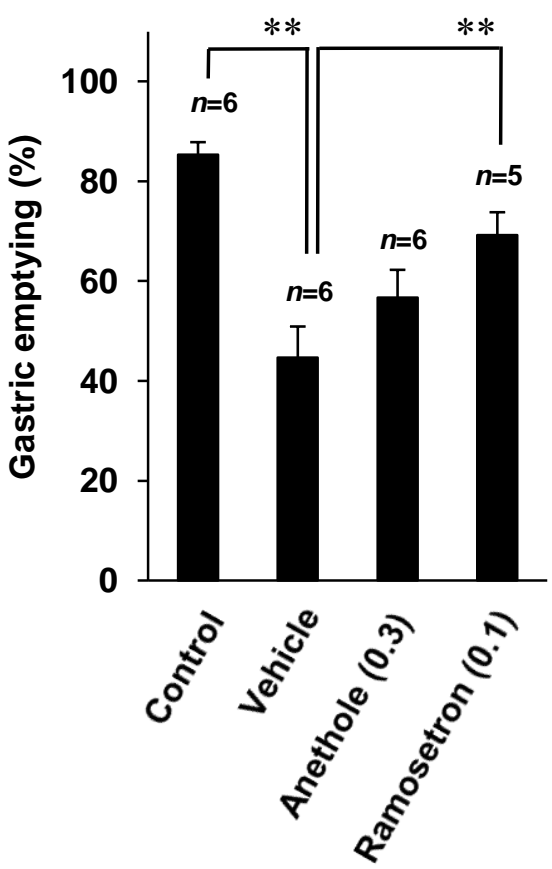

D

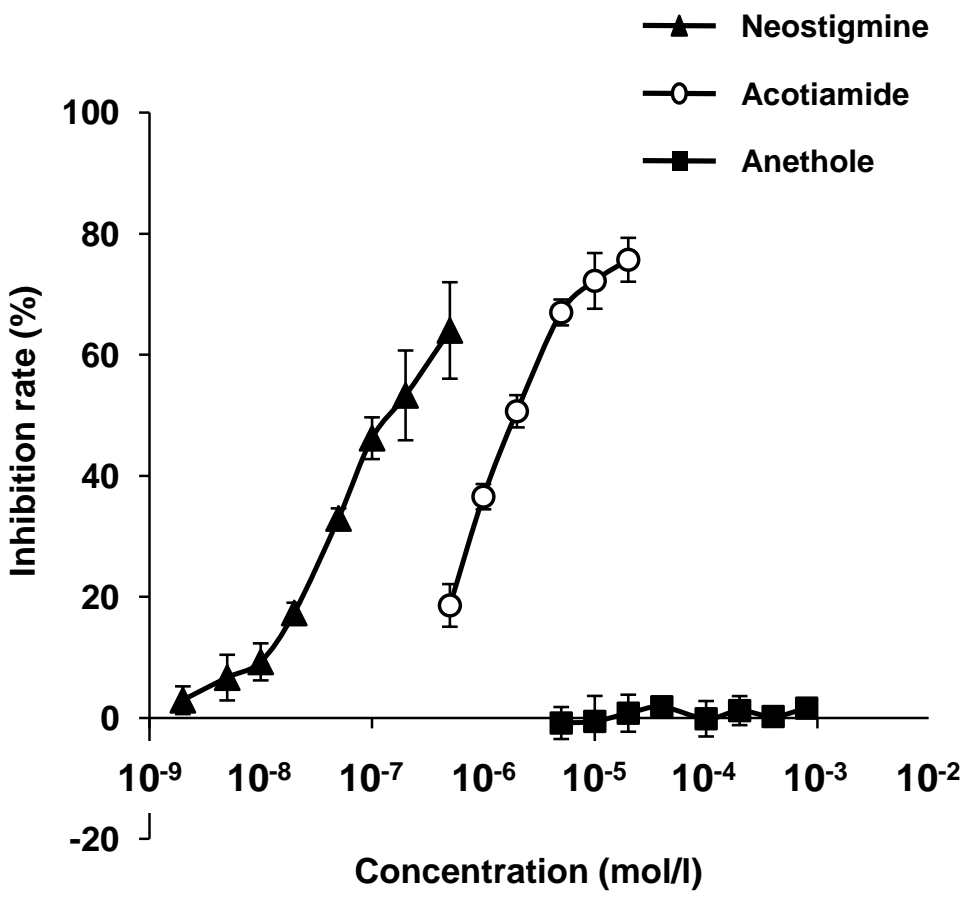


A - $\rightarrow--$ Vehicle $(n=22)$

Anethole (0.03) ( $n=11)$

$\longrightarrow$ Anethole (0.3) (n=10)

- $\square--$ Anethole (3) $(n=10)$

-0 - Acotiamide (300) (n=9)

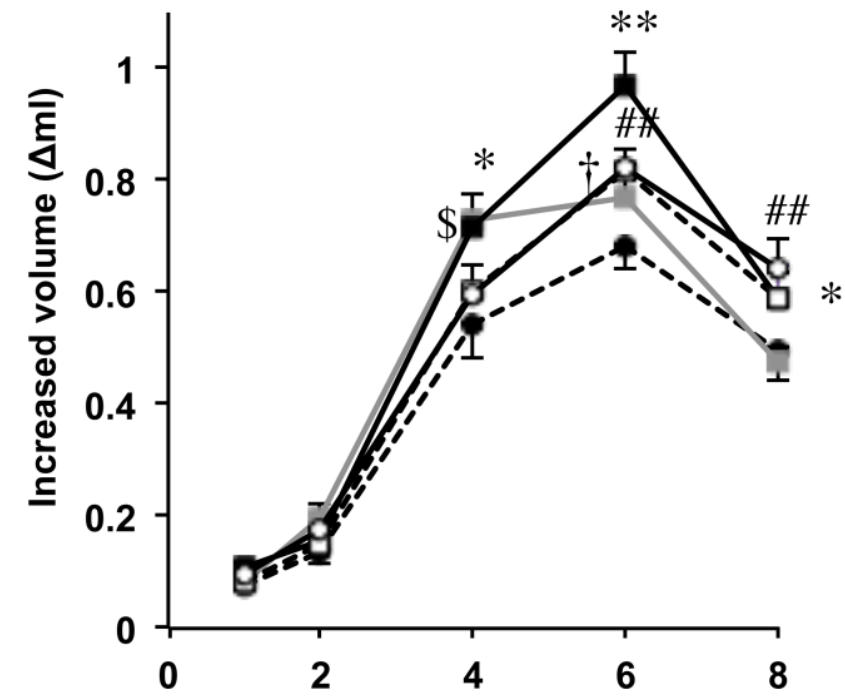

Balloon pressure $(\mathrm{mmHg})$
B

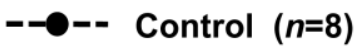

- - WRS+Vehicle $(n=10)$

$\longrightarrow$ WRS+Anethole (0.3) (n=5)

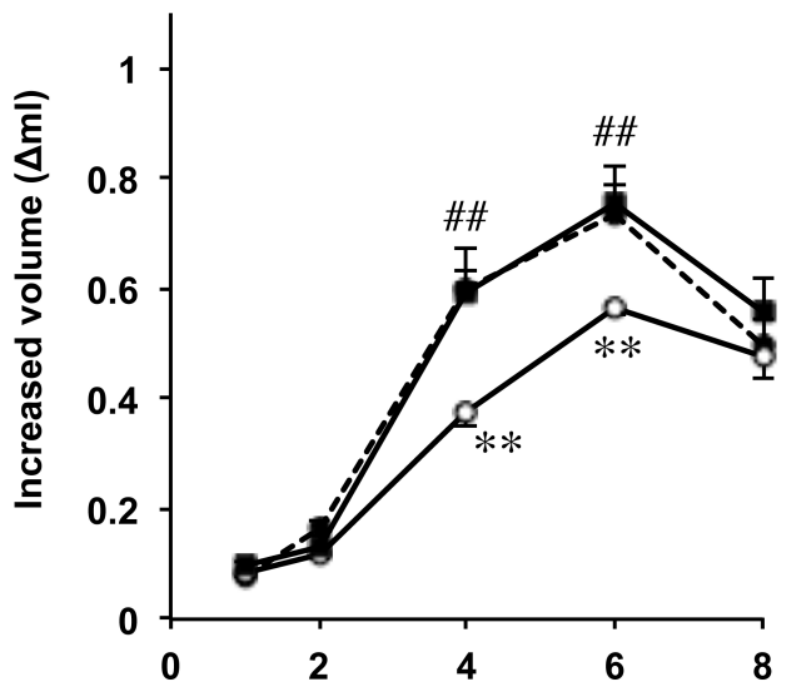

Balloon pressure $(\mathrm{mmHg})$ 